\author{
Holstein종 젖소의 선형심사형질에 대한 유전모수추정 \\ 이기환*·상병찬**·남명수** · 도창희** • 최재관*·조광현* \\ 농촌진흥청 국립축산과학원*, 충남대학교 낙농산업과학과**
}

\title{
Estimation of Genetic Parameter for Linear Type Traits in Holstein Dairy Cattle in Korea
}

Ki Hwan Lee*, Byung Chan Sang**, Myoung Soo Nam**, Changhee Do**, Jae Gwan Choi* and Kawng Hyun Cho*

National Institute of Animal Science, R. D. A*, Dept. of Dairy Science \& Industry, Cheongnam National University**

\begin{abstract}
This study utilized 332,625 records of linear type scores consisting for 15 primary traits, 22,175 final score and 84,612 pedigree information of 22,175 Holstein cows from 1993 to 2007 in Korea to estimate genetic parameters for 16 type traits. Genetic and error (co)variances between two traits selected from 16 traits were estimated using bi-trait pairwise analyses with DFREML package. The estimated heritabilities for stature (ST), strength (STR), body depth (BD), dairy form (DF), rump angle (RA), thurl width (TW), rear legs side view (RLSV), foot angle (FA), fore udder attachment (FUA), rear udder height (RUH), rear udder width (RUW), udder cleft (UC), udder depth (UD), front teat placement (FTP), front teat length (FTL) and final score (FS) were $0.31,0.21,0.25,0.10,0.29,0.19,0.09,0.06,0.12,0.13,0.12,0.08,0.26,0.20,0.28$ and 0.15 , respectively. ST had the highest positive genetic correlation with $\mathrm{BD}(0.90)$, while RLSV had the highest negative genetic correlation with FA $(-0.56)$. RA had negative genetic correlation with most udder traits $(-0.17 \sim-0.02)$. Especially, RUW had the higher positive genetic correlation with STR (0.60), BD (0.62), and TW (0.49), however, UD had the higher negative genetic correlation with STR $(-0.40)$ and BD (-0.40). FTL had negative genetic correlation with FUA, RUH, RUW, UC and UD. FS had positive genetic correlation with UC, UD and FTP $(0.12,0.18$ and 0.20). However, additional research is needed on the use of these parameters in the genetic evaluation because estimated genetic and error variance-covariance matrices were not positive definite.
\end{abstract}

(Key words : Linear type trait, Genetic parameter, Holstein cow)

\section{I. 서 론}

최근 젖소의 산유능력은 괄목할 만 한 증가를 하였으나 경제적 수명에 도달하지 못하고 도태되고 있는 실정에 있 다. 그에 따라 고능력우가 장수하여 생애산유량을 증대시 키는 것에 대한 관심이 점차 높아지고 있다. 따라서 젓소 의 경제수명을 늘려 생애산유량을 증대시키기 위해서는 젖소의 신체적 기능과 밀접한 관련이 있는 기능적 체형형 질의 개량이 무엇보다도 중요하다고 볼 수 있다. 체형형 질 중에서 기능적 중요도가 높다고 알려진 선형형질과 산 유형질과의 연관성에 대한 연구가 보고되어 (Harris 등, 1992; Short와 Lawlor, 1992; Misztal, 1992; Vollema와 Groen, 1997) 젖소육종계획 수립에 사용되고 있다. 젖소의 경제수명은 산유. 번식능력자료와 함께 선형형질을 조사 하여 젖소유전능력평가에 이용하면 보다 정확한 능력예측 이 가능하다(Foster 등, 1989; Short 등, 1992; DeGroot 등,
2002). 그러나 현재까지 젖소개량을 위한 자료 수집이나 평가에 있어 생산형질에 대해서는 많은 연구가 이루어진 반면 선형형질의 경우에는 충분하지 않았다. 따라서 본 연구는 국내 홀스타인종 젖소의 혈통 및 선형심사형질에 대한 자료를 기초로 유전모수를 추정하여 향후 장수성 등 에 대한 국내 젖소의 육종계획 수립에 필요한 기초 자료 를 얻기 위해 수행하였다.

\section{․ 재료 및 방법}

\section{1. 공시재료}

본 연구에는 1998 2007년도까지 한국종축개량협회의 주 관으로 실시된 선형심사자료 중 초산차의 유생산기록을 갖는 22,175 두의 홀스타인종 암소에 해당되는 84,612두의 혈통기록, 332,625 개의 선형심사 점수와 22,175 개의 최종 
점수를 이용하였다. 선형심사형질은 심사자에 의해 1 50 점의 단계로 점수화되었으며 점수부여 기준은 한국종축개 량협회의 표준평가방법 (한국종축개량협회, 2007)을 적용하 였다(Table 1). 혈통자료는 한국종축개량협회의 혈통등록기 록을 이용하였으며 기존 우리나라 유전능력평가에 이용되 어온 혈통을 기초로 하여 선형심사검정자료에 따른 각 개 체의 혈통경로의 추적을 실시하여 세대순으로 정렬한 뒤 각 검정우에 대해 일련번호를 부여하여 분석에 이용하였다.

유효자료의 선정을 위하여 먼저 젖소의 생년월일, 심사 일, 최근분만일, 등록번호, 심사시 연령, 비유단계와 심사 자에 따른 형질별 점수에 대한 결측치 검사와 $3 \mathrm{SD}$ (표준 편차) 범위를 벗어나는 이상치를 제거하였다. 그리고 한 개체가 2 개 이상의 자료를 가졌을 경우에는 마지막 심사 일에 해당하는 자료를 뽑았고, 심사자의 심사 빈도가 매 우 낮고 심사자를 알 수 없는 자료는 제거하였다. 우군, 심사년도, 심사자별 관측수가 5 개 이상인 개체의 심사기 록만을 이용하였고, 유전모수추정의 정확도를 높이기 위 하여 우군(농가)의 혈통기록에서 최소한 아비를 알고 있 거나 부모의 기록이 모두 존재하는 비율이 $70 \%$ 이상인 그룹만 우군수준에 포함시켜 분석하였다. 심사시 연령은 월령으로 바꾼 뒤 정규성 검정에 따라 15 개월령 미만과 80 개월령을 초과하는 성적은 분석에서 제외하였고, 2 세 이하에서 5 세 이상까지 총 3 단계로 나누어 분석에 이용하 였다. 분만 후 비유단계 (lactation stage)는 착유 305일까지 를 유효자료로 간주하여 1 개월 단위로 총 12 수준으로 분 류한 뒤 7수준 이상의 빈도수가 매우 적게 나타나 7수준 이상은 모두 7단계로 간주하여 분석모형에 적용시켰다.
교정을 거쳐 분석에 이용된 각 요인의 수준별 관측치수 및 혈통정보는 Table 2 와 같다. 그리고 우군은 총 1,675 개 가 이용되었다.

\section{2. 유전모수추정}

모형설정을 위해 우군, 심사년도, 심사자, 심사시연령 그리고 비유단계를 고려하여 분석하였으며, 우군, 심사년 도 그리고 심사자의 효과가 주요인으로서의 효과뿐만 아 니라 요인간의 효과가 분석된 모든 형질에 대해 나타나 3 가지 요인을 결합하여 하나의 고정효과인 $\mathrm{HYC}$ 로서 모형 에 적용하였다. 각 형질에 대한 상가적 유전효과에 대한 유전모수 및 유전상관을 추정하기 위하여 DFREML패키지 를 이용하였다 (Meyer, 1987, 1988). 유전 및 오차 분산-공 분산은 16 개 형질에서 2 개 형질씩 짝을 지어 총 225 개 형 질조합에 대하여 이형질 (二形質) 모형을 이용하여 추정하 였으며, 두 형질 모두 동일모형을 적용하였다. 유전분산은 각 조합에서 추정한 값의 평균을 이용하였고, 공분산은 각 형질조합에서 추정된 값을 그대로 이용하였다. 분산성 분 추정시 우도함수값의 수렴조건은 $10^{-8}$ 으로 하였다.

$$
\mathrm{Y}=\mathrm{Xb}+\mathrm{Zu}+\mathrm{e}
$$

여기서,

$\mathrm{Y}=$ 선형형질에 대한 관측치 벡터

$\mathrm{X}=$ 고정효과에 대한 계수행렬 (우군-심사년도-심사 자, 심사연령, 비유단계에 대한 벡터)

$\mathrm{Z}=$ 개체효과에 대한 계수행렬

Table 1. Definition of linear type traits of Holstein cows

\begin{tabular}{|c|c|c|c|}
\hline \multirow{2}{*}{ Trait (abbr.) } & \multicolumn{3}{|c|}{ Score } \\
\hline & $1 \leftarrow$ & 25 & $\rightarrow 50$ \\
\hline Stature (ST) & Extremely short & Intermediate & Extremely tall \\
\hline Strength (STR) & Narrow and frail & Intermediate & Strong and wide \\
\hline Body depth (BD) & Shallow body & Intermediate & Extremely deep body \\
\hline Dairy form (DF) & Thick and coarse & Sharp and angular & Extremely sharp angular \\
\hline Rump angle (RA) & $\begin{array}{l}\text { Pins clearly higher } \\
\text { then hooks }\end{array}$ & $\begin{array}{l}\text { Slight slope from hooks } \\
\text { to pins }\end{array}$ & $\begin{array}{l}\text { Extremely sloped from } \\
\text { hooks to pins }\end{array}$ \\
\hline Thurl width (TW) & Extremely narrow & Intermediate & Extremely wide \\
\hline Rear legs side view (RLSV) & Postry and straight & Intermediate set in hock & Extremely sickled \\
\hline Foot angle (FA) & Extreme low angle & Intermediate & Extremely steep angle \\
\hline Fore udder attachment (FUA) & Loose & Intermediate strength & Snug and strong \\
\hline Rear udder height (RUH) & Extremely low & Intermediate & Extremely high \\
\hline Rear udder width (RUW) & Narrow rear udder & Intermediate & Extremely wide \\
\hline Udder cleft (UC) & $\begin{array}{l}\text { Negative cleft, broken } \\
\text { support }\end{array}$ & $\begin{array}{l}\text { Clearly defined halving, } \\
\text { cleft and support }\end{array}$ & $\begin{array}{l}\text { Extreme cleft and strong } \\
\text { support }\end{array}$ \\
\hline Udder depth (UD) & $\begin{array}{l}\text { Very deep, udder floor } \\
\text { well below the hock }\end{array}$ & Udder floor above hocks & $\begin{array}{l}\text { Extreme height of udder } \\
\text { floor above hock }\end{array}$ \\
\hline Front teat placement (FTP) & Wide & Intermediate & Close \\
\hline Front teat length (FTL) & Extremely small & Intermediate & Extremely large \\
\hline
\end{tabular}


Table 2. Number of observation on records by each factors considered on model

\begin{tabular}{|c|c|c|c|c|c|c|c|c|c|}
\hline \multicolumn{2}{|c|}{$\begin{array}{c}\text { Year at } \\
\text { classification }\end{array}$} & \multicolumn{2}{|c|}{$\begin{array}{c}\text { Age at } \\
\text { classification }\end{array}$} & \multicolumn{2}{|c|}{ Lactation stage } & \multicolumn{2}{|c|}{ Classifier } & \multicolumn{2}{|c|}{ Summary of pedigree structure } \\
\hline Year & $\mathrm{N}$ & Age & $\mathrm{N}$ & Stage & $\mathrm{N}$ & Class. & $\mathrm{N}$ & & $\mathrm{N}$ \\
\hline 1998 & 1,216 & 1 & $7,7,518$ & 1 & 3,605 & $\mathrm{~A}$ & $5,5,378$ & "base" animals & 10,924 \\
\hline 1999 & 1,469 & 2 & 6,207 & 2 & 4,439 & $\mathrm{~B}$ & 4,584 & Animals with records & 20,212 \\
\hline 2000 & 1,965 & 3 & 6,487 & 3 & 3,900 & $\mathrm{C}$ & 4,097 & Sires with progeny records & 833 \\
\hline 2001 & 2,334 & & & 4 & 3,396 & $\mathrm{D}$ & 2,048 & Dams with progeny records & 12,814 \\
\hline 2002 & 1,723 & & & 5 & 2,713 & $\mathrm{E}$ & 1,938 & Grand-sires w. progeny records & 1,123 \\
\hline 2003 & 2,291 & & & 6 & 1,489 & $\mathrm{~F}$ & 2,167 & Grand-dams w. progeny records & 7,975 \\
\hline 2004 & 1,936 & & & $\geqq 7$ & 670 & & & & \\
\hline 2005 & 2,673 & & & & & & & & \\
\hline 2006 & 3,343 & & & & & & & & \\
\hline 2007 & 1,262 & & & & & & & & \\
\hline Total & 20,212 & & 20,212 & & 20,212 & & 20,212 & & 53,064 \\
\hline
\end{tabular}

$\mathrm{b}=$ 알려지지 않은 고정효과에 대한 추정치 벡터

$\mathrm{u}=$ 개체효과에 대한 추정치 벡터 $\mathrm{N}(0, \mathrm{G} \otimes \mathrm{A}), \mathrm{G}=$ 상가 적유전 분산-공분산 행렬, $\mathrm{A}=$ 혈연계수 행렬

$\mathrm{e}=$ 임의 잔차 벡터 $\sim \mathrm{N}(0, \mathrm{R}), \mathrm{R}=$ 잔차 분산 - 공분산 행렬

\section{III. 결과 및 고찰}

\section{1. 일반능력}

분석된 선형심사 점수와 종합점수의 기초통계량을 Table 3에 제시하였다. 이후 선형형질은 키 (ST), 강건성 (STR), 체심 $(\mathrm{BD})$, 예각성 $(\mathrm{DF})$, 엉덩이의 기울기 (RA), 엉 덩이의 너비 (TW), 옆에서 본 뒷다리의 상태 (RLSV), 발굽 의 각도(FA), 앞유방의 붙음성 (RUA), 뒷유방의 높이 $(\mathrm{RUH})$, 정중제인대 (UC), 유방깊이 (UD), 뒤에서 본 앞유두 배열 $(\mathrm{FTP})$, 앞유두의 길이 $(\mathrm{FTL})$, 최종점수 $(\mathrm{FS})$ 와 같이 약 자를 사용하여 설명하겠다.

최종점수를 제외한 15 개 선형형질의 평균은 ST가 33.32 로 가장 높았고 STR이 21.95로 가장 낮았다. ST는 33.32 점으로 Vanraden 등 (1990), Short 등 (1991), Misztal 등 (1992), Short와 Lawlor(1992b), Weigel 등 (1997), Tsuruta 등 (2005)의 보고에서의 27.1 32.2 보다 높았고, 이와 김 (2006)의 33.3과는 같은 결과였으며, 이상적인 점수대 $(25$ 점 이상)에 속했다. 국내 젖소의 키는 외국의 보고와 비슷 한 것으로 나타났다. 그러나 일반적인 건강상태와 고비유 능력을 나타내는 STR은 21.95로 외국의 보고(Thompson 등, 1981; Boldman과 Famula, 1985; Foster 등, 1988; Vanraden 등, 1990; Short 등, 1991; Misztal 등, 1992; Short 와 Lawlor, 1992; Weigel 등, 1997)에서의 22.8 30에 비해 상당히 낮았고 이상적인 점수대 (25점 이상)에도 미치지
Table 3. Basic statistic for the 15 linear type traits and final score in Holstein cows

\begin{tabular}{lcc}
\hline Trait (abbr.) & Obs. & Mean \pm SD \\
\hline \hline Stature (ST) & 20,212 & $33.32 \pm 7.8$ \\
Strength (STR) & 20,212 & $21.95 \pm 6.5$ \\
Rump angle (RA) & 20,212 & $26.08 \pm 7.5$ \\
Thurl width (TW) & 20,212 & $24.06 \pm 6.9$ \\
Dairy form (DF) & 20,212 & $24.57 \pm 6.0$ \\
Body depth (BD) & 20,212 & $23.30 \pm 6.5$ \\
Rear legs side view (RLSV) & 20,212 & $27.78 \pm 6.0$ \\
Foot angle (FA) & 20,212 & $24.41 \pm 6.9$ \\
Fore udder attachment (FUA) & 20,212 & $25.39 \pm 7.6$ \\
Rear udder height (RUH) & 20,212 & $25.32 \pm 8.2$ \\
Rear udder width (RUW) & 20,212 & $24.08 \pm 7.8$ \\
Udder cleft (UC) & 20,212 & $25.37 \pm 6.7$ \\
Udder depth (UD) & 20,212 & $25.62 \pm 8.1$ \\
Front teat placement (FTP) & 20,212 & $22.72 \pm 7.2$ \\
Front teat length (FTL) & 20,212 & $24.19 \pm 7.9$ \\
Final score (FS) & 20,212 & $75.84 \pm 3.4$ \\
\hline
\end{tabular}

못하여 이에 대한 개량이 시급하다고 사료되었다. 전체 선형형질 중 가장 낮은 비율 $(10 \%)$ 을 차지하지만 많은 양 의 사료를 섭취할 수 있는 능력과 관련된 중요한 형질로 서, 높은 산유량 달성을 위해 고려되어야 하는 형질인 $\mathrm{BD}$ 는 23.30점으로 이상적인 점수 (25점 이상)에 미치지 못하 였고, 외국의 보고 (Thompson 등, 1981; Boldman과 Famula, 1985; Foster 등, 1988; Vanraden 등, 1990; Short 등, 1991; Misztal 등, 1992; Short와 Lawlor, 1992; Weigel 등, 1997)에 서의 23.2 32와 비교해도 낮게 평가되었다. 젖소가 비유기 를 통하여 얼마나 많은 우유를 생산할 수 있는지를 예측 할 수 있게 해주는 유용특질의 형질인 $\mathrm{DF}$ 는 24.57점으로 처음 선형심사를 실시한 1984년 (21.48)에 비해 개량된 것 으로 나타났고 (한국종축개량협회 1993c-삭제할것), 이상적 
인 점수대(25점 이상)에 근접했지만 아직 외국의 보고 (Short 등, 1991; Short와 Lawlor, 1992; Weigel 등, 1997)에 서의 25.1 30.6과 비교해 낮게 나타났다. 배설과 재번식 성에 직접 관련이 있는 $\mathrm{RA}$ 는 26.08점으로 이상적인 점수 대 (20 30)에 속하였고, 외국의 보고 (Vanraden 등, 1990; Short 등, 1991; Misztal 등, 1992; Short와 Lawlor, 1992; Weigel 등, 1997; Tsuruta 등, 2005)에서의 24.6 25.8 보다 높았다. 송아지분만의 용이함과 유방의 너비와 직접적인 연관이 있기 때문에 넓을수록 좋은 형질인 $\mathrm{TW}$ 는 24.06점 으로 이상적인 점수대 (20 30)를 나타냈지만, 외국의 보고 (Foster 등, 1988; Vanraden 등, 1990; Short 등, 1991; Misztal 등, 1992; Short와 Lawlor, 1992; Weigel 등, 1997)에 서의 26.8 29에 비해 좁게 평가되었다. 선형형질 중 지구 력과 체중의 효율적인 유지와 관련되어 생산수명과 연관 된 형질로서 이와 관련된 RLSV는 27.78점으로 이상적인 점수대인 20 30의 범위였고, 외국의 보고(Thompson 등, 1981; Vanraden 등, 1990; Short 등, 1991; Short와 Lawlor, 1992; Weigel 등, 1997)에서의 27.2 27.4와 비슷했다. 지제 의 지구력과 운동성을 보여주는 발굽기울기 (FA)는 24.41 로 이상적인 점수대 (25점 이상)에 근접했고, 이 등 (1996) 이 23.62, 이와 김 (2006)이 21.35로 보고한 것보다 높았다. 젖소의 생산 수명과 연관되어 단단히 붙어 있어야 좋은 형질인 $\mathrm{FUA}$ 는 25.39로 이상적인 점수인 25점에 근접하였 고, Misztal 등 (1992)이 보고한 25.5와 비슷하였으며, Weigel 등 (1997)의 24.1과 Tsuruta 등 (2005)의 22.3의 보고 보다는 높게 나타났다. 이는 우리나라 젖소가 나이를 먹 을수록 유방이 많이 처져 생산수명이 단축되는 현상이 줄 어들었기 때문이라고 사료되었다. 유방의 비유능력(용적) 과 유생산의 잠재력을 보여주는 RUH와 RUW는 각각
25.32와 24.08점으로 Tsuruta 등(2005)의 24.4와 23.3보다 높게 평가되었다. 착유의 용이성 및 유방의 부착정도를 알 수 있는 UC는 25.37점으로 이상적인 점수대 (25 40)에 근접했지만, Weigel 등(1997)의 26.4, Tsuruta 등 (2005)의 27.9에 비해 낮았다. 유방형질 중 가장 큰 비중을 갖고 있 는 $\mathrm{UD}$ 는 25.62점으로 이상적인 점수대 (25 30)에 근접하였 으며, 외국의 보고(Misztal 등, 1992; Weigel 등, 1997)의 $27.22,27.3$ 점 보다 낮았고, 이 등 (1996)의 25.30과 이와 김 (2006)이 보고한 24.3 보다 높았다. FTP와 FTL은 22.72와 24.19로서 외국의 보고(Vanraden 등, 1990; Misztal 등, 1992; Weigel 등, 1997; Tsuruta 등, 2005) 보다 낮고, 이상 적인 점수대 (25 30)에 미치지 못한 것으로 나타났다. 전체 적으로 국내 홀스타인 종 젖소의 유방형질은 몇몇 형질을 제외하고는 외국의 기록과 비슷하게 평가되었으며 이상적 인 점수대에 근접하였다. 또한 우리나라 젖소의 개량 정 도를 나타내는 FS의 평균값은 75.84점으로 평가되어 Good [G] 수준 (75 79)에 속하였는데 이는 앞에서 말했듯이 유 생산력과 직접적인 연관이 있는 비유기관에 해당되는 형 질에 대한 개량이 이루어지고 있기 때문이라고 판단되었 다. 하지만 이제 Good [G]의 최소 수준에 도달하였고 최종 점수가 낙농선진국에 비해 낮아 국제수준의 체형에 이르 기 위해서는 이들 형질에 대한 지속적인 개량이 필요하다 고 사료되었다.

2. 심사시 연령 (age)과 비유단계 (lactation stage)에 따 른 최소자승평균

각 형질의 심사연령 및 비유단계의 수준별 효과를 알아 보기 위해 분석한 최소자승평균 및 표준오차는 Table 4와

Table 4. Least square mean (LSM) and standard error (SE) of the 15 linear type traits and final scores by age at classification

\begin{tabular}{|c|c|c|c|c|}
\hline \multirow{2}{*}{ Age } & $\mathrm{LSM} \pm \mathrm{SE}$ & $\mathrm{LSM} \pm \mathrm{SE}$ & $\mathrm{LSM} \pm \mathrm{SE}$ & $\mathrm{LSM} \pm \mathrm{SE}$ \\
\hline & ST & STR & $\mathrm{BD}$ & $\mathrm{DF}$ \\
\hline 1 & $30.28 \pm 0.099$ & $19.06 \pm 0.078$ & $19.80 \pm 0.077$ & $22.17 \pm 0.077$ \\
\hline 2 & $33.75 \pm 0.097$ & $22.18 \pm 0.076$ & $23.37 \pm 0.076$ & $24.20 \pm 0.076$ \\
\hline \multirow[t]{2}{*}{3} & $36.19 \pm 0.097$ & $25.64 \pm 0.076$ & $27.05 \pm 0.076$ & $25.88 \pm 0.076$ \\
\hline & RA & TW & RLSV & FA \\
\hline 1 & $25.73 \pm 0.100$ & $20.16 \pm 0.081$ & $26.50 \pm 0.079$ & $25.88 \pm 0.090$ \\
\hline 2 & $25.78 \pm 0.098$ & $24.14 \pm 0.080$ & $27.55 \pm 0.078$ & $24.26 \pm 0.089$ \\
\hline \multirow[t]{2}{*}{3} & $26.11 \pm 0.098$ & $28.01 \pm 0.080$ & $29.41 \pm 0.078$ & $22.59 \pm 0.089$ \\
\hline & FUA & RUH & RUW & $\mathrm{UC}$ \\
\hline 1 & $25.38 \pm 0.102$ & $24.22 \pm 0.107$ & $20.28 \pm 0.097$ & $26.35 \pm 0.088$ \\
\hline 2 & $25.42 \pm 0.100$ & $25.11 \pm 0.105$ & $23.96 \pm 0.096$ & $25.56 \pm 0.086$ \\
\hline \multirow[t]{2}{*}{3} & $24.65 \pm 0.100$ & $24.43 \pm 0.106$ & $26.06 \pm 0.096$ & $24.51 \pm 0.086$ \\
\hline & UD & FTP & FTL & FS \\
\hline 1 & $30.73 \pm 0.093$ & $23.27 \pm 0.096$ & $21.99 \pm 0.104$ & $74.75 \pm 0.044$ \\
\hline 2 & $26.24 \pm 0.091$ & $22.96 \pm 0.094$ & $24.25 \pm 0.102$ & $75.88 \pm 0.043$ \\
\hline 3 & $20.27 \pm 0.091$ & $22.45 \pm 0.094$ & $25.86 \pm 0.102$ & $76.47 \pm 0.043$ \\
\hline
\end{tabular}


Table 5. Least square mean (LSM) and standard error (SE) of the 15 linear type traits and final scores by lactation stage at classification

\begin{tabular}{|c|c|c|c|c|c|c|c|c|}
\hline \multirow{2}{*}{ Stage } & $\mathrm{LSM} \pm \mathrm{SE}$ & $\mathrm{LSM} \pm \mathrm{SE}$ & $\mathrm{LSM} \pm \mathrm{SE}$ & $\mathrm{LSM} \pm \mathrm{SE}$ & $\mathrm{LSM} \pm \mathrm{SE}$ & $\mathrm{LSM} \pm \mathrm{SE}$ & $\mathrm{LSM} \pm \mathrm{SE}$ & $\mathrm{LSM} \pm \mathrm{SE}$ \\
\hline & ST & STR & $\mathrm{BD}$ & DF & RA & TW & RLSV & FA \\
\hline 1 & $33.29 \pm 0.124$ & $21.09 \pm 0.097$ & $22.47 \pm 0.097$ & $24.47 \pm 0.097$ & $26.55 \pm 0.125$ & $23.78 \pm 0.101$ & $27.39 \pm 0.099$ & $24.78 \pm 0.113$ \\
\hline 2 & $33.42 \pm 0.111$ & $21.65 \pm 0.087$ & $23.59 \pm 0.087$ & $26.04 \pm 0.087$ & $26.52 \pm 0.113$ & $24.48 \pm 0.091$ & $27.80 \pm 0.089$ & $24.60 \pm 0.102$ \\
\hline 3 & $33.68 \pm 0.118$ & $22.38 \pm 0.093$ & $24.08 \pm 0.092$ & $25.70 \pm 0.093$ & $26.21 \pm 0.120$ & $24.57 \pm 0.097$ & $28.09 \pm 0.095$ & $24.24 \pm 0.108$ \\
\hline 4 & $33.72 \pm 0.127$ & $22.59 \pm 0.100$ & $23.83 \pm 0.099$ & $24.40 \pm 0.099$ & $26.05 \pm 0.128$ & $24.51 \pm 0.104$ & $28.10 \pm 0.101$ & $23.92 \pm 0.116$ \\
\hline 5 & $33.44 \pm 0.142$ & $22.73 \pm 0.111$ & $23.68 \pm 0.111$ & $23.44 \pm 0.111$ & $25.39 \pm 0.143$ & $24.28 \pm 0.116$ & $27.90 \pm 0.113$ & $24.07 \pm 0.130$ \\
\hline 6 & $33.44 \pm 0.192$ & $22.66 \pm 0.151$ & $23.19 \pm 0.150$ & $22.44 \pm 0.150$ & $25.16 \pm 0.195$ & $23.81 \pm 0.158$ & $27.75 \pm 0.154$ & $24.22 \pm 0.176$ \\
\hline & $32.86 \pm 0.287$ & $22.94 \pm 0.226$ & $23.01 \pm 0.224$ & $22.11 \pm 0.224$ & $25.23 \pm 0.291$ & $23.29 \pm 0.235$ & $27.71 \pm 0.229$ & $23.86 \pm 0.262$ \\
\hline & FUA & RUH & RUW & $\mathrm{UC}$ & UD & FTP & FTL & FS \\
\hline 1 & $25.94 \pm 0.127$ & $27.51 \pm 0.134$ & $25.54 \pm 0.122$ & $23.37 \pm 0.110$ & $24.75 \pm 0.116$ & $21.06 \pm 0.120$ & $23.62 \pm 0.130$ & $76.02 \pm 0.055$ \\
\hline 2 & $25.90 \pm 0.114$ & $26.99 \pm 0.121$ & $26.01 \pm 0.110$ & $25.44 \pm 0.099$ & $24.76 \pm 0.104$ & $22.20 \pm 0.108$ & $24.90 \pm 0.117$ & $76.60 \pm 0.049$ \\
\hline 3 & $25.32 \pm 0.122$ & $25.51 \pm 0.129$ & $24.87 \pm 0.117$ & $25.76 \pm 0.105$ & $25.04 \pm 0.111$ & $23.13 \pm 0.114$ & $24.82 \pm 0.124$ & $76.33 \pm 0.052$ \\
\hline 4 & $25.14 \pm 0.130$ & $24.08 \pm 0.138$ & $23.54 \pm 0.125$ & $25.76 \pm 0.113$ & $25.50 \pm 0.119$ & $23.25 \pm 0.122$ & $24.54 \pm 0.133$ & $75.83 \pm 0.056$ \\
\hline 5 & $24.91 \pm 0.146$ & $23.44 \pm 0.154$ & $22.22 \pm 0.140$ & $26.09 \pm 0.126$ & $26.17 \pm 0.133$ & $23.76 \pm 0.137$ & $23.91 \pm 0.149$ & $75.54 \pm 0.062$ \\
\hline 6 & $24.54 \pm 0.197$ & $22.63 \pm 0.209$ & $21.25 \pm 0.189$ & $25.93 \pm 0.171$ & $27.08 \pm 0.180$ & $23.57 \pm 0.186$ & $23.48 \pm 0.202$ & $75.02 \pm 0.085$ \\
\hline 7 & $24.31 \pm 0.295$ & $21.96 \pm 0.312$ & $20.60 \pm 0.283$ & $25.96 \pm 0.255$ & $26.93 \pm 0.269$ & $23.28 \pm 0.277$ & $22.94 \pm 0.301$ & $74.58 \pm 0.127$ \\
\hline
\end{tabular}

5 에 나타내었다.

ST, STR, BD, DF, RA, TW, RLSV, RUW, FTL과 FS는 심사연령이 지날수록 증가하는 것으로 나타났다. 반면 $\mathrm{FA}, \mathrm{FUA}, \mathrm{UC}, \mathrm{UD}$ 와 FTP는 심사연령이 증가함에 따라 평 가점수가 낮아지는 것으로 나타났다.

ST에 대한 최소자승평균은 가장 높은 평균을 나타냈으 며 큰 점수변화가 없었다. STR은 점차 증가했다. $\mathrm{BD}$ 은 3 단계까지 증가하다가 4단계부터는 점차 감소하였다. $\mathrm{DF}$ 는 2 단계에서 가장 높았다가 점차 감소하였다. RA, TW와 FA 는 비유단계에 따라 심사점수가 약간 낮아졌다. RUH와 RUW는 뚜렷하게 낮아졌는데, 이는 유방의 용적을 나타내 는 형질로서 유생산의 잠재력 측면에서 고려하면 비유단 계가 지날수록 비유량이 적어지는 것과 관계가 있다고 판 단되었다. 그리고 $\mathrm{UC}$ 와 $\mathrm{UD}$ 는 점차 증가했다. 이는 $\mathrm{UC}$ 가 이와 김 (2006)이 비유단계와 비유형질 간에 관련성이 타 형질보다 다소 적다는 보고와는 상이한 결과였다. FTP 5 단계까지 증가하다가 이후 낮아지는 경향을 보였다. FTL 은 2 단계에서 가장 높았다가 점차로 낮아졌다. 이는 젖소 가 새끼를 분만한 후 유두배열 및 유두의 길이가 최고 비 유기까지 변화하다가 이후 변화가 약화된다는 보고(이 등, 2006)와 유사한 결과를 보였다. 최종점수는 2 단계에서 가장 높았다가 점차로 낮아지는 경향을 나타내었는데 Hayes와 Mao (1987)의 연구보고와 유사한 결과였다.

\section{3. 유전력}

분석된 15 개의 선형형질점수와 최종점수에 대한 유전분 산과 유전력을 Table 6에 제시하였다.
Table 6. Genetic parameter for 15 linear type traits and final scores in Holstein cows

\begin{tabular}{lrrc}
\hline Traits & \multicolumn{1}{c}{$\sigma_{\mathrm{a}}^{2}$} & $\sigma_{\mathrm{e}}^{2}$ & $\mathrm{~h}^{2}$ \\
\hline \hline Stature & 13.55 & 30.37 & 0.31 \\
Strength & 5.72 & 21.86 & 0.21 \\
Rump angle & 15.51 & 37.95 & 0.29 \\
Thurl width & 5.74 & 24.04 & 0.19 \\
Dairy form & 2.87 & 25.35 & 0.10 \\
Body depth & 6.99 & 20.67 & 0.25 \\
Rear legs side view & 2.84 & 27.49 & 0.09 \\
Foot angle & 2.21 & 34.62 & 0.06 \\
Fore udder attachment & 5.40 & 41.15 & 0.12 \\
Rear udder height & 6.70 & 42.97 & 0.13 \\
Rear udder width & 4.71 & 36.24 & 0.12 \\
Udder cleft & 3.29 & 36.16 & 0.08 \\
Udder depth & 11.18 & 31.64 & 0.26 \\
Front teat placement & 9.57 & 37.33 & 0.20 \\
Front teat length & 15.80 & 40.55 & 0.28 \\
Final Score & 1.32 & 7.36 & 0.15 \\
\hline
\end{tabular}

$\sigma_{\mathrm{a}}^{2}$ : additive genetic variance, $\sigma_{\mathrm{e}}^{2}$ : error variance, $\mathrm{h}^{2}$ : heritability

Table 6을 보면 유전력은 FA가 0.06으로 가장 낮았고, ST가 0.31로 가장 높았다. ST에 대한 유전력은 0.31로 DeGroot 등 (2002)과 Tsuruta 등 (2005)이 보고한 0.47과 0.46 보다 낮았고 이 등 (1996)이 보고한 0.31과는 같았다. STR의 유전력은 0.21로 DeGroot 등 (2002)과 Tsuruta 등 (2005)이 보고한 0.41과 0.33보다 낮았고 이 등 (1996)의 0.148 보다 높았다. RA의 유전력은 0.29 로 DeGroot 등 (2002)과 Tsuruta 등 (2005)이 보고한 0.36과 0.38 보다 낮았 다. TW의 유전력은 0.19로 이 등 (1996), DeGroot 등 (2002) 
과 Tsuruta 등(2005)이 보고한 0.21 0.30 보다 낮았다. DF 의 유전력은 0.10으로 Weigel 등 (1997), DeGroot 등 (2002) 과 Tsuruta 등 (2005)이 보고한 $0.3,0.36,0.35$ 보다 낮았고, 이 등 (1996)이 보고한 0.13과는 비슷하였다. $\mathrm{BD}$ 의 유전력 은 0.25로 이 등 (1996)의 0.21 보다 높았으나, Weigel 등 (1998), DeGroot 등 (2002), Tsuruta 등 (2005)이 보고한 0.33, $0.36,0.41$ 에 비해 낮았다. RLSV의 유전력은 0.09 로 이 등 (1996), Weigel 등 (1998), Tsuruta 등 (2005)의 보고인 0.17, $0.16,0.19$ 에 비해 낮았지만, DeGroot 등 (2002)이 보고한 0.11 과는 비슷하게 추정됐다. FA의 유전력은 0.06으로 이 등 (1996), Weigel 등 (1998), Tsuruta 등 (2005)이 보고한 0.1, $0.14,0.12$ 에 비해 낮았지만, DeGroot 등 (2002)이 보고한 0.04 에 비해 높았다. 유생산성과 장수성 및 장래 잠재적 생산력과 관련된 유방관련 형질 중에서 $\mathrm{UD}$ 에 대한 유전 력은 0.08로 추정되어 이 등(1996), Weigel 등(1997)과 Tsuruta 등 (2005)의 보고에서 $0.08,0.14$ 와 0.2 로 추정한 것 과 유사하게 유방형질 중 가장 낮은 유전력을 보였다. 나 머지 FUA, RUH와 RUW 대한 유전력도 0.12 0.13으로 상 기의 외국의 보고에 비해 낮았고, FTL에 대한 유전력도 0.28로 DeGroot 등 (2002)이 보고한 0.29와 비슷했으며, Tsuruta 등 (2005)이 보고한 0.2에 비해 높게 추정되었다. FTP에 대한 유전력은 0.2로 Thompson 등 (1981)이 0.19, Vanraden 등 (1990)이 0.21, Boldman 등 (1992)이 0.2로 보고 한 것과 비슷하게 추정되었다. $\mathrm{UD}$ 는 0.26 으로 추정되어 외국의 보고에 비해 높았다 (Thompson 등, 1983; Foster 등, 1989; Vanraden 등, 1990; Short 등, 1991; Boldman 등, 1992; Short와 Lawlor, 1992; DeGroot 등, 2002). 이와 같이 유방관련 형질 중에서는 $\mathrm{UD}, \mathrm{FTL}$ 이 비교적 높게 추정되
어, 타형질에 비해 유전적인 개량속도가 빠르고, 개량가능 성이 높을 것으로 사료되었다. 마지막으로 최종점수의 유 전력은 0.15로 이 등 (1996), Thompson 등 (1983), Short와 Lawlor(1992) 그리고 Tsuruta 등(2005)이 보고한 0.22, $0.28,0.26$ 과 0.28 에 비해 낮게 추정되었다. 전체적으로 유 전력은 외국의 연구보고에 비해 낮게 추정되어 추후에 더 많은 개체의 선형형질에 대한 심사 및 혈통자료의 정확한 조사가 이루어져야 하며, 심사점수에 영향을 미치는 심사 자, 산차, 심사연령 및 비유단계, 사육환경 등과 같은 여 러 요인의 효과에 대한 지속적인 연구를 통해 적절한 모 형을 설정하여 추정의 정확도를 높여야 할 것으로 사료되 었다.

\section{4. 유전상관 및 표현형상관}

상가적 유전분산과 공분산 (Table 7)을 이용하여 15 개 선 형형질 간에 유전상관 및 표현형상관을 추정하여 Table 8 에 제시하였다.

$\mathrm{STR}$ 과 $\mathrm{BD}$ 의 유전상관은 0.90 으로 가장 높은 상관을 보 여주었는데, 이는 Vanraden 등 (1990)이 보고한 0.93, Misztal 등(1992)이 보고한 0.9, Short와 Lawlor(1992)가 보 고한 0.92 와 비슷하였다. 또한 RLSV와 FA간에는 -0.56 의 가장 높은 부(-)의 상관을 보여, 외국의 보고(Foster 등, 1988; Vanraden 등, 1990; Short 등, 1991; Misztal, 1990; Short와 Lawlor, $1992 \mathrm{~b}$; DeGroot 등, 2002)와 같은 경향을 나타냈다. $\mathrm{ST}, \mathrm{STR}, \mathrm{BD}, \mathrm{DF}$ 는 상호간에 모두 정 $(+)$ 의 상 관을 보여 이 등 (1996)과 DeGroot (2002) 등의 연구보고와 같았으며, STR과 TW간에 0.62의 높은 상관을 나타냈다.

Table 7. Additive-genetic (above diagonal) and error covariance (below diagonal) matrix for the 15 linear type traits and final scores using pair-wise analysis

\begin{tabular}{|c|c|c|c|c|c|c|c|c|c|c|c|c|c|c|c|c|}
\hline & ST & STR & $\mathrm{BD}$ & DF & RA & TW & RLSV & FA & FUA & RUH & RUW & $\mathrm{UC}$ & UD & FTP & FTL & $\mathrm{FS}$ \\
\hline ST & & 3.18 & 4.58 & 2.48 & 1.42 & 4.85 & -1.07 & 2.52 & 1.43 & 0.61 & 2.76 & -0.15 & 2.68 & 0.33 & 1.73 & 2.59 \\
\hline STR & 7.27 & & 5.58 & 0.95 & -0.77 & 3.59 & -1.32 & 0.00 & 1.06 & -0.50 & 3.21 & -0.72 & -3.20 & -0.05 & 1.94 & 1.64 \\
\hline $\mathrm{BD}$ & 7.49 & 12.35 & & 2.20 & -0.92 & 3.74 & -0.63 & 0.02 & 1.16 & 0.06 & 3.61 & -0.51 & -3.60 & 0.32 & 1.13 & 2.00 \\
\hline DF & 2.58 & 2.15 & 6.31 & & -0.36 & 1.22 & 0.76 & -0.04 & 0.77 & 1.95 & 2.00 & 0.52 & -0.65 & 0.58 & 0.25 & 1.21 \\
\hline RA & 4.97 & -0.73 & 0.70 & 0.94 & & -1.59 & 0.24 & 0.55 & -1.59 & -0.87 & -0.18 & 0.57 & -1.21 & -0.49 & 1.07 & -0.59 \\
\hline TW & 7.59 & 7.53 & 8.29 & 4.37 & 0.35 & & -0.16 & 0.14 & 0.45 & -0.31 & 2.55 & -0.90 & -1.64 & 0.03 & 1.91 & 1.35 \\
\hline RLSV & -1.47 & -0.06 & 0.30 & 2.67 & 2.50 & 0.46 & & -1.39 & -0.44 & 0.12 & -0.61 & 0.24 & -0.27 & 0.23 & -0.06 & -0.74 \\
\hline FA & 2.86 & 2.82 & 2.05 & 0.28 & -3.38 & 2.25 & -10.08 & & 0.12 & 0.26 & 0.49 & 0.82 & 1.13 & 0.42 & -0.57 & 0.61 \\
\hline FUA & 0.75 & 2.92 & 3.08 & 4.53 & -2.46 & 2.37 & -1.69 & 4.17 & & 2.53 & 1.77 & 0.18 & 4.77 & 2.03 & -1.95 & 1.75 \\
\hline RUH & 1.50 & 1.02 & 1.50 & 7.16 & 1.37 & 2.70 & -0.84 & 3.04 & 12.97 & & 2.98 & 1.86 & 3.87 & 1.08 & -1.18 & 1.82 \\
\hline RUW & 3.80 & 6.27 & 7.13 & 8.20 & -1.00 & 7.70 & -1.14 & 3.66 & 9.40 & 14.55 & & -0.11 & -1.75 & 0.63 & -0.16 & 2.10 \\
\hline $\mathrm{UC}$ & 0.61 & 0.33 & 1.27 & 4.50 & -1.46 & 1.59 & 0.42 & 1.54 & 6.41 & 8.19 & 4.60 & & 2.60 & 2.19 & -2.55 & 0.26 \\
\hline UD & 0.20 & -2.98 & -4.14 & -0.32 & -0.84 & -2.34 & -0.05 & 2.88 & 9.33 & 6.52 & -4.09 & 6.91 & & 1.46 & -2.29 & 0.72 \\
\hline FTP & -0.29 & 1.24 & 1.66 & 1.62 & -0.65 & 1.40 & 0.35 & 1.03 & 6.44 & 1.76 & 2.29 & 7.21 & 5.18 & & -4.75 & 0.73 \\
\hline FTL & 4.47 & 3.17 & 3.92 & 1.43 & -1.17 & 3.20 & -0.87 & 1.73 & 2.23 & 2.78 & 5.54 & 2.09 & -1.99 & -2.44 & & -0.48 \\
\hline FS & 3.41 & 4.05 & 5.08 & 6.70 & -0.67 & 4.10 & -1.24 & 4.30 & 7.68 & 8.50 & 8.89 & 4.67 & 2.27 & 2.91 & 2.30 & \\
\hline
\end{tabular}

Note: variance-covariance matrix is not positive definite. 
Table 8. Additive-genetic (above diagonal) and phenotypic (below diagonal) correlation matrix for the 15 linear type traits and final scores

\begin{tabular}{crrrrrrrrrrrrrrrr}
\hline & ST & STR & BD & DF & RA & TW & RLSV & FA & FUA & RUH & RUW & UC & UD & FTP & FTL & FS \\
\hline \hline ST & & .36 & .47 & .39 & .10 & .55 & -.17 & .45 & .17 & .06 & .34 & -.02 & .22 & .03 & .12 & .60 \\
STR & .30 & & .90 & .23 & -.08 & .62 & -.33 & .00 & .19 & -.08 & .60 & -.17 & -.40 & -.01 & .20 & .60 \\
BD & .35 & .65 & & .49 & -.09 & .59 & -.14 & .01 & .19 & .01 & .62 & -.11 & -.40 & .04 & .11 & .67 \\
DF & .14 & .11 & .30 & & -.05 & .30 & .27 & -.02 & .20 & .44 & .54 & .17 & -.11 & .11 & .04 & .62 \\
RA & .13 & -.04 & -.01 & .02 & & -.17 & .04 & .09 & -.17 & -.09 & -.02 & .08 & -.09 & -.04 & .07 & -.13 \\
TW & .34 & .39 & .42 & .19 & -.03 & & -.04 & .04 & .08 & -.05 & .49 & -.20 & -.20 & .00 & .20 & .49 \\
RLSV & .07 & -.05 & -.01 & .12 & .07 & .01 & & -.56 & -.11 & .03 & -.17 & .08 & -.06 & .04 & -.01 & -.37 \\
FA & .13 & .09 & .06 & .01 & -.06 & .07 & -.34 & & .03 & .07 & .15 & .31 & .22 & .09 & -.10 & .35 \\
FUA & .05 & .11 & .12 & .15 & -.08 & .08 & -.06 & .10 & & .42 & .36 & .04 & .59 & .28 & -.21 & .65 \\
RUH & .05 & .01 & .04 & .24 & .01 & .06 & -.02 & .08 & .32 & & .54 & .40 & .44 & .13 & -.11 & .61 \\
RUW & .15 & .28 & .32 & .30 & -.03 & .29 & -.05 & .11 & .26 & .39 & & -.03 & -.24 & .09 & -.02 & .82 \\
UC & .01 & -.01 & .02 & .15 & -.02 & .02 & .02 & .06 & .15 & .23 & .11 & & .42 & .39 & -.35 & .12 \\
UD & .07 & -.18 & -.22 & -.03 & -.04 & -.11 & -.06 & .10 & .32 & .23 & -.14 & .23 & & .14 & -.17 & .18 \\
FTP & .00 & .03 & .05 & .06 & -.02 & .04 & .02 & .03 & .18 & .06 & .07 & .22 & .15 & & -.38 & .20 \\
FTL & .12 & .13 & .13 & .04 & .00 & .12 & -.02 & .03 & .01 & .03 & .11 & -.01 & -.09 & -.14 & & -.10 \\
FS & .31 & .37 & .46 & .51 & -.06 & .34 & -.12 & .27 & .47 & .50 & .58 & .27 & .16 & .18 & .08 & \\
\hline
\end{tabular}

$\mathrm{RA}$ 와 유방형질 간의 유전상관은 $\mathrm{UC}$ 를 제외하고는 -0.17 에서 -0.02 로 모두 부 $(-)$ 의 상관을 보여 이 등 $(1996)$, Thompson 등 (1981), Forster 등 (1988), Vanraden 등 (1990), Misztal 등 (1992), Short와 Lawlor (1992b) 그리고 DeGroot 등 (2002)의 보고와 유사하였다. FUW는 STR, BD, RUW에 대하여 각각 $0.60,0.62,0.49$ 로 높은 정 $(+)$ 의 상관을 나타 냈다. $\mathrm{UD}$ 는 $\mathrm{STR}$ 과 $\mathrm{BD}$ 에 대하여 -0.40 의 높은 부 $(-)$ 의 유전상관을 나타냈다. 유방형질 간의 유전상관 결과에서 는 FTL이 FUA, RUH, RUW, UC, UD 그리고 FTP와 부 $(-)$ 의 상관을 나타냈다. $\mathrm{FTL}$ 은 $\mathrm{FUA}, \mathrm{UC}, \mathrm{FTP}$ 와 각각 $-0.21,-0.35,-0.38$ 의 높은 부 $(-)$ 의 유전상관을 나타냈 다. 전반적으로 형질 간의 유전상관은 외국에서 연구보고 와 비슷하였다. 하지만, STR과 FA 그리고 RUW와 FTP간 의 유전상관이 0.00 으로 추정되어 외국의 보고(Thompson 등, 1981; Foster 등, 1988; Misztal 등, 1992; Short와 Lawlor, 1992b; DeGroot 등, 2002)에서 정 $(+)$ 의 상관으로 추정된 것과는 차이가 있었다. 그리고 $\mathrm{FS}$ 는 $\mathrm{UC}, \mathrm{UD}$ 그리 고 $\mathrm{FTP}$ 와의 유전상관이 각각 $0.12,0.18,0.2$ 로 낮게 추정 되어 국내의 연구(이 등, 1996)와는 비슷했지만, 외국의 연구 (Short와 Lawlor, 1992b)에서 각각 0.65, 0.59, 0.64로 보고한 것과 큰 차이를 보여 이에 대한 연구가 필요한 것 으로 사료되었다.

선형형질에 대한 심사점수의 평균을 살펴보면 대부분의 선형형질에 있어서 우리나라 홀스타인종 젖소우군에 대해 개량이 이루어져 체형이 우수한 젓소가 생산되고 있음을 알 수 있었다. 하지만 추정된 유전력을 보면 처음 심사가 시작되었을 때의 점수보다는 높아졌지만, 낙농선진국의 연구보고에 비해서 대체로 낮은 유전력을 나타내어 선형
심사점수에 영향을 미치는 기타 환경요인(심사자, 심사연 령, 우군, 비유단계 및 산차 등)에 대한 정확한 요인분석 과 보정방법에 대한 연구가 이루어져야 할 것으로 사료되 었다. 또한 유전 및 잔차 분산-공분산 행렬이 양정치를 나타내지 않았기 때문에 유전능력평가에 이용하기 위해서 는 이에 대한 추가적인 연구가 필요할 것으로 판단되었다. 또한, 현재 일부 목장의 젖소우군에 대해서만 실시되고 있는 선형심사가 전국적으로 확대되어 지금보다 더 많은 우군의 선형형질에 대한 조사가 이루어져야 할 것으로 사 료되었다. 이러한 추가적인 연구를 통해 생산 및 번식형 질과 함께 선형형질에 대하여 지속적으로 관심을 가지고, 정확하게 유전능력을 평가한다면, 우리나라 젓소의 선형 형질에 대한 적절한 개량이 이루어질 것으로 사료된다.

\section{IV. 요 약}

본 연구는 1998부터 2007년도까지 수집된 국내 홀스타 인종 22,175 두의 15 개 형질에 대한 332,625 개의 선형심사 점수, 22,175 개의 최종점수와 84,612 개의 혈통정보를 이용 하여 유전모수를 추정하기 위해 실시하였다. 유전 및 오 차 분산-공분산은 16 개 형질에서 2 개 형질씩 짝을 지어 총 225 개 형질조합에 대하여 이형질 (二形質) 모형을 이용 하여 DFREML 패키지로 추정하였다. 키 $(\mathrm{ST})$, 강건성 (STR), 체심 $(\mathrm{BD})$, 예각성 $(\mathrm{DF})$, 엉덩이 기울기 $(\mathrm{RA})$, 엉덩 이 너비 (TW), 옆에서 본 뒷다리 (RLSV), 발굽기울기 (FA), 앞유방의 붙음성 (FUA), 뒷유방의 부착높이 (RUH), 뒷유방 의 너비 $(\mathrm{RUW})$, 정중제인대 $(\mathrm{UC})$, 유방의 깊이 (UD), 뒤에 서 본 앞유두의 배열위치 (FTP), 앞유두의 길이 (FTL) 그리 
고 최종점수 $(\mathrm{FS})$ 에 대한 유전력은 각각 $0.31,0.21,0.25$, $0.10,0.29,0.19,0.09,0.06,0.1,0.293,0.1,0.20,0.196$ $0.190,0.28$ 그리고 0.15 로 추정되었다. 키는 강건성과 0.9 의 가장 높은 정 $(+)$ 의 상관을 나타냈다. 반면, 옆에서 본 뒷다리는 발굽기울기와 -0.56 의 가장 높은 부 $(-)$ 의 상관 을 나타냈다. 엉덩이 기울기는 정중제인대를 제외한 유방 형질과 -0.17 에서 -0.02 의 부 $(-)$ 의 상관을 보였다. 특 히 뒷유방의 너비는 강건성 (0.60), 체심 $(0.62)$, 엉덩이 너 비 $(0.49)$ 와 높은 정 $(+)$ 의 유전상관을 나타냈다. 반면, 유방 깊이는 강건성 $(-0.4)$, 체심 $(-0.4)$ 과 높은 부 $(-)$ 의 유전 상관을 보였다. 앞유두의 길이는 앞유방의 붙음성, 뒷유방 의 부착높이, 뒷유방의 너비, 정중제인대 그리고 유방의 깊이와 모두 부 $(-)$ 의 유전상관을 나타냈다. 최종점수는 정중제인대 $(0.12)$, 유방의 깊이 $(0.18)$, 그리고 뒤에서 본 앞유두의 배열위치 $(0.2)$ 와 정 $(+)$ 의 유전상관을 보였다. 하 지만 유전 및 잔차 분산-공분산 행렬이 양정치 행렬이 아닌 것으로 나타났기 때문에 유전능력평가에 이용하기 위해서는 주의가 필요하며, 모든 형질에 대한 유전상관을 동시에 추정하는 등의 추가적인 연구가 필요할 것으로 사 료되었다.

$$
\mathrm{V} \text {. 사 사 }
$$

본 연구에 이용된 국내 홀스타인종 젖소의 혈통정보와 선형심사 자료를 제공해주신 한국종축개량협회의 관계자 분들께 진심으로 감사의 말씀을 드립니다.

\section{VI. 인 용 문 헌}

1. Boldman, K. G. and Famula, T. R. 1985. Association of sire dystocia transmitting ability with progeny linear type traits in Holsteins. J. Dairy Sci. 68:2052-2057.

2. Boldman, K. G. and Van Vleck, L. D. 1991. Derivative-Free restricted maximum likelihood estimation in animal models with a sparse matrix solver. J. Dairy Sci. 74:4337-4343.

3. Boldman, K. G., Freeman, A. E., Freeman., Harris, B. L. and Kuck, A. L. 1992. Prediction of sire transmitting abilities for herd life from transmitting abilities for linear type traits. J. Dairy Sci. 75:552-563.

4. DeGroot, B. J., Keown, J. F., Van Vleck, L. D. and Marotz, E. L. 2002. Genetic parameters and responses of linear type, yield traits, and somatic cell scores to divergent selection for predicted transmitting ability for type in Holsteins. J. Dairy Sci. 85:1578-1585.

5. Foster, W. W., Freeman, A. E., Berger, P. J. and Kuck, A. 1988. Linear type trait analysis with genetic parameter estimation. J. Dairy Sci. 71:223-231.

6. Foster, W. W., Freeman, A. E., Berger, P. J. and Kuck, A. 1989. Association of type traits scored linearly with production and herdlife of Holsteins. J. Dairy Sci. 72:2651-2664.

7. Harris, B. L., Freeman, A. E. and Metzger, E. 1992. Genetic and phenotypic parameters for type and production in Guernsey dairy cows1. J. Dairy Sci. 75:1147.

8. Hayes, A. E. and Mao, I. L. 1987. Effect of parity, age and stage of lactation at classification on linear type scores of Holstein cattle. J. Dairy Sci. 70:1898.

9. Meyer, K. 1987. Restricted Maximum Likelihood(REML) programs for the analysis of animal breeding data. Program notes prepared for a workshop in Orange, NSW, March 2-6, Mimeo. 55.

10. Meyer, K. 1988. Estimation of variance components for Individual Animal Models $\Pi$. Multivariate analyses. Genet. Sel. Evol. (submitted)

11. Misztal, I., Lawlor, T. J. and Short, T. H. 1992. Multiple-trait estimation of variance components of yield and type traits using an animal model. J. Dairy Sci. 75:544-551.

12. Short, T. H., Lawlor, T. J. JR. and Lee, K. L. 1991. Genetic parameters for three experimental linear type traits. J. Dairy Sci. 74:2020-2025.

13. Short, T. H. and Lawlor. 1992a. Revised udder composite can increase longevity. Holstein world p. 44.

14. Short, T. H. and Lawlor. 1992b. Genetic parameters of conformation traits, milk yield, and herd life in Holsteins. J. Dairy Sci. 75:1987-1998.

15. Tsuruta, S., Misztal, I. and Lawlor. 2005. Changing definition of productive life in US Holsteins: Effect on genetic correlations. J. Dairy Sci. 88:1156-1165.

16. Vanraden, P. M., Jensen, E. L., Lawlor, T. J. and Funk, D. A. 1990. Prediction of transmitting abilities for Holstein type traits. J. Dairy Sci. 73:191-197.

17. Vollema, ANT. R. and Groen, AB. F. 1997. Genetic correlations between longevity and conformation traits in an upgrading dairy cattle population. J. Dairy Sci. 80:3006-3014.

18. Weigel, D. J., Cassell, B. G. and Pearson, R. E. 1997. Prediction of transmitting abilities for productive life and lifetime profitability from production, somatic cell count, and type traits in milk markets for fluid milk and cheese. J. Dairy Sci. 80:1398-1405.

19. 김시동, 박병호, 서강석, 윤호백, 조광현, 최재관. 2005. 동물 육종을 위한 통계패키지 사용설명서 III. DFREML. 농촌진흥 청 국립축산과학원.

20. 이광전, 박경도 조주현, 김경남. 1996. 홀스타인 젖소의 체형 형질과 생산형질들에 대한 유전모수 추정. 한국축산학회지. 38(5):455.

21. 이득환, 김은길. 2006. Holstein 젖소의 선형심사형질과 등급 형질에 대한 환경효과 분석. 한국동물자원과학회지. 48(6): 767-776.

22. 한국종축개량협회. 2006. 2006년도 젖소 등록 및 심사기술. pp29-49.

(접수일자 : 2009. 8. 4. / 수정일자 : 2009. 10. 13. /

채택일자 : 2009. 10. 20.) 